\title{
Biomechanical evaluation and surface characterization of a nano-modified surface on PEEK implants: a study in the rabbit tibia
}

This article was published in the following Dove Press journal:

International Journal of Nanomedicine

14 August 2014

Number of times this article has been viewed

\author{
Pär Johansson' \\ Ryo Jimbo' \\ Per Kjellin ${ }^{2}$ \\ Fredrik Currie 2 \\ Bruno Ramos Chrcanovic' \\ Ann Wennerberg' \\ 'Department of Prosthodontics, \\ Faculty of Odontology, Malmö \\ University, Malmö, Sweden; ${ }^{2}$ Promimic \\ AB, Göteborg, Sweden
}

\begin{abstract}
Polyether ether ketone (PEEK) is today frequently used as a biomaterial in different medical operations due to its excellent mechanical and chemical properties. However, the untreated surface of PEEK is bioinert and hydrophobic, and it does not osseointegrate in its pure form. The aim of this study was to evaluate a unique nano-modified surface of PEEK with respect to osseointegration. Forty-eight threaded, non-cutting PEEK implants were inserted bilaterally in the tibia of 24 rabbits. Half of the implants $(n=24)$ were coated with nanocrystalline hydroxyapatite (test) and the remaining implants $(n=24)$ were left uncoated (control). Half of the animals $(n=12)$ were euthanized after 3 weeks of healing and the remaining $(n=12)$ after 12 weeks. The implant retention was measured with a removal torque apparatus. Surface analysis was performed with interferometry, scanning electron microscopy, and X-ray photon spectroscopy to relate the removal torque to the applied surface. The test implants revealed a significantly higher retention after 3 weeks $(P=0.05)$ and 12 weeks $(P=0.028)$ compared to controls. The result of the present study proves that the addition of nanocrystalline hydroxyapatite coating to PEEK surfaces significantly increases its removal torque and biocompatibility.
\end{abstract}

Keywords: polyether ether ketone, hydroxyapatite, removal torque, nanotopography

\section{Introduction}

Polyether ether ketone (PEEK) is a semi-crystalline thermoplastic material that has been used in situations where robustness and chemical resistance at high temperatures is required. In addition to its excellent mechanical properties, PEEK is chemically inert and resistant to sterilization. ${ }^{1-8}$ These features may be of great advantage for a biomaterial. PEEK has been used in orthopedic applications for decades and in the late 1990s, became widely used as a substitute for metal implants in spinal surgery. Due to PEEK's translucency to X-rays, radiographic evaluation is more accessible and precise, which simplifies the postoperative evaluation and decisions for further treatment. ${ }^{7,9}$ By reinforcing PEEK with carbon fibers, the elastic modulus can be approximated to that of the cortical bone, which has been suggested to decrease stress shielding after spinal surgery compared to metal implants. ${ }^{4,10-14}$

The untreated surface of PEEK is bioinert and hydrophobic and it does not osseointegrate. ${ }^{5}$ To convert the PEEK surface to be hydrophilic and osteoconductive, different techniques have been evaluated. It has been reported that by applying hydroxyapatite (HA) to PEEK, either mixed with the polymer or applied onto its surface, PEEK becomes more hydrophilic and possesses bioactivity. ${ }^{15,16} \mathrm{HA}$ has been found to be an excellent coating material for enhanced osseointegration and previous studies have shown a significantly increased rate of bone formation compared to untreated surfaces. ${ }^{17-20}$ The modification converts the PEEK from bioinert
Correspondence: Pär Johansson

Department of Prosthodontics,

Faculty of Odontology, Malmö University,

20506 Malmö, Sweden

Tel +464066585I4

Email par.johansson@mah.se 
to bioactive, since the synthesized HA bound to the implant surface blends into the natural HA in the bone. ${ }^{21} \mathrm{~A}$ commonly applied surface-coating method is the plasma spray technique. Plasma-sprayed HA implants have been found to significantly enhance and accelerate the early stages of bone formation. ${ }^{22}$ Furthermore, the effect of plasma-sprayed coating has been notable in situations where a gap exists between the implant and the bone, in which plasma-sprayed coats compensated for this gap and promoted further bone regeneration. ${ }^{23}$ However, clinical long-term complications with the use of plasma-sprayed HA have been documented. ${ }^{24}$ Rokkum et al found that the use of some thick-layered apatitecoated implants resulted in severe inflammation and bone resorption due to detachment of the coating material. ${ }^{25}$ It was identified histologically that multinucleated giant cells were localized in the proximity of the implant, and many of the cells resided around the detached HA particles. Registad et al have shown that plasma HA coating presents a gradual decrease in biomechanical fixation, which was observed for up to 52 weeks in a rabbit tibia. Furthermore, this histologic observation presented HA flake detachment and multinucleated giant cell infiltration in the proximity of the implant. ${ }^{26}$

To utilize the excellent bioactive properties of HA and to suppress the negative responses of thick HA layers, such as the detachment of the particles and osteoclastic reactions, a thinner and rigid HA coating may be desirable. With a thin HA coating, it is possible to retain the micro roughness of the implant substrate. We have previously shown in several studies that a thin layer of nanostructured HA obtained by a wet chemical-based technique may significantly enhance osseointegration. ${ }^{27,28}$ With a thickness of 10-20 nm and HA crystals with similar size and shape as those found in human bone, it was suggested that the novel coating facilitates implant integration. ${ }^{27,29,30}$ Furthermore, since the nanosized HA coating is a monolayer, the risk of detachment is hypothesized to be lower than that of the thicker HA coatings. A recently published study, using an identical HA coating as in the present study, revealed a higher mean bone-to-implant contact for HA, indicating a higher level of osseointegration. ${ }^{31}$ Conversely, due to an unfavorable implant design, a large number of implants were lost due to a lack of primary stability. The design of the implant in the present study has taken into account the result of the previous study in order to achieve better primary stability. Therefore, the implant was provided with non-cutting threads to increase its primary stability. Instead of a pin-shaped implant with the flat top outside the cortical bone, the implant was redesigned to be fully submerged into the bone.
Due to the improved bioactivity and stable HA nanocoating around the PEEK material, it was hypothesized that the interfacial bonding strength would be significantly higher for the nano HA-coated implant surface compared to the non-coated PEEK material. Thus, the aim of the present study was to investigate the effect of a nano HA coating on PEEK implants placed in rabbit tibias after 3 and 12 weeks in vivo.

\section{Materials and methods Implant preparation}

Forty-eight threaded, non-cutting PEEK implants of $4 \mathrm{~mm}$ length and $3.5 \mathrm{~mm}$ diameter were manufactured for the study (Invibio Ltd., Thornton-Cleveleys, UK; Figure 1). Half of the implants $(\mathrm{n}=24)$ were coated with $\mathrm{HA}^{\text {nano }}$ Surface (test; Promimic AB, Göteborg, Sweden) and the remaining ( $n=24)$ implants were left uncoated (control). For the implants to be coated, $50 \mu \mathrm{L}$ of coating solution was applied onto the top of each implant, and the implant was allowed to rotate at 2,700 rpm for 5 seconds. The coating solution contains nanosized HA crystals that have been suspended with surfactants and solvent. The crystals are $20-50 \mathrm{~nm}$ long and 2-10 nm wide. After the coating step, the PEEK implant was put into an oven with an oxygen-enriched atmosphere at $325^{\circ} \mathrm{C}$ for 5 minutes. This heat treatment was done in order to remove
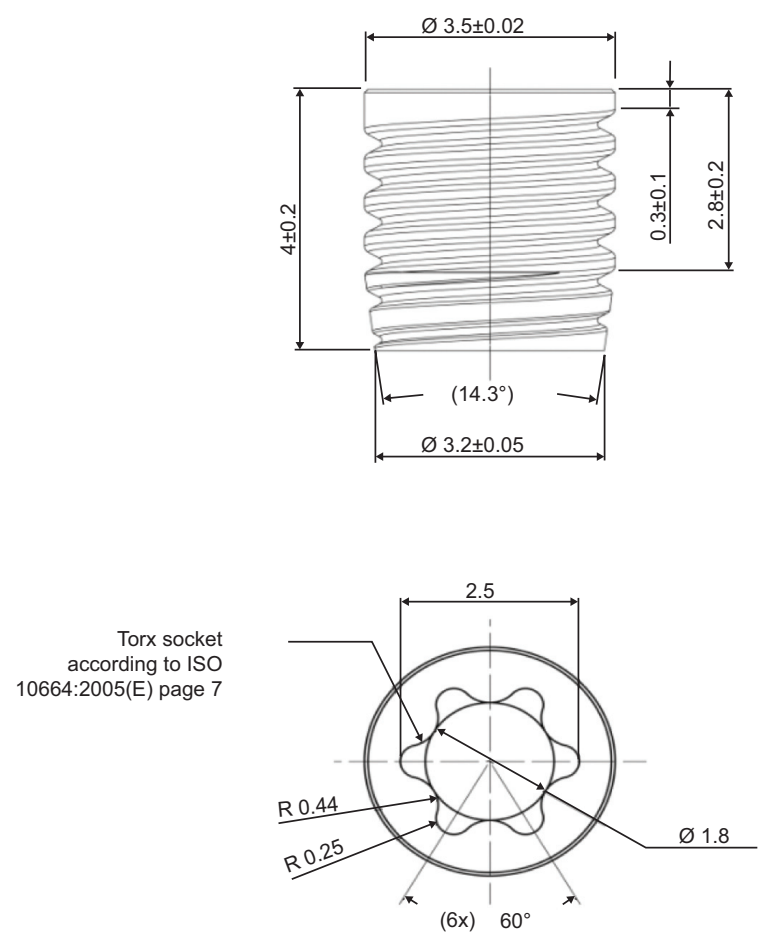

Figure I Technical drawing of a PEEK implant.

Abbreviations: ISO, International Organization for Standardization; PEEK, polyether ether ketone. 
the stabilizing surfactants and to attach the HA crystals onto the PEEK substrate.

\section{Surface characterization Interferometry}

The surface topography at the micrometer level was characterized with an interferometer (MicroXAM; ADE Phase Shift, Tucson, AZ, USA). The selected measurement area was $200 \times 260 \mu \mathrm{m}(\times 50$ objective, zoom factor 0.625$)$. A Gaussian filter of $50 \times 50 \mu \mathrm{m}$ was applied for removal of errors of form and waviness. Three samples from each group were measured $(n=6)$ each on three tops, flanks, and valleys of the threads (nine measurements per implant) according to guidelines by Wennerberg and Albrektsson. ${ }^{32}$ The following topographical parameters were selected for surface characterization: $\mathrm{S}_{\mathrm{a}}$ $(\mu \mathrm{m})=$ average deviation in height in relation to a prenominal plane; $\mathrm{S}_{\mathrm{ds}}\left(\mu \mathrm{m}^{-2}\right)=$ density of summits, a spatial parameter; and $\mathrm{S}_{\mathrm{dr}}(\%)=$ the developed surface ratio to a flat surface.

\section{Atomic force microscopy (AFM)}

The surface topography at the nanometer level was characterized with an AFM (XE-100; Park Systems, Suwon, South Korea). Measurements were performed on discs since the microscope provides better resolution when used on a flat surface compared to a cylindrical one. Three discs of each PEEK group were analyzed on three random positions $(n=6)$. Measurements were performed in a non-contact mode at room temperature with two scan areas, $1 \times 1 \mu \mathrm{m}$ and $10 \times 10 \mu \mathrm{m}$. After leveling by subtraction, a Gaussian filter was applied $(0.25 \mu \mathrm{m}$ and $1 \mu \mathrm{m}$, respectively). Graphic 3D images were processed with the imaging software MountainsMap (Digital Surf, Besançon, France).

\section{Scanning electron microscopy (SEM)}

Illustrative images of the surface were obtained with an SEM (LEO Ultra 55 FEG; Zeiss, Oberkochen, Germany). The implants were sputtered with gold prior to analysis to make the surface conductive. Micrographs were obtained at two magnifications ( $10 \mathrm{~K}$ and $80 \mathrm{~K}$ ) at diverse selected areas.

\section{Chemical characterization}

\section{X-ray photon spectroscopy (XPS)}

Chemical assessment of the surface was performed with an XPS (PHI 5000C ESCA System; PerkinElmer Inc., Waltham, MA, USA). Spectra were obtained at an operating angle of $45^{\circ}$, at $200 \mathrm{~W}$ with an $\mathrm{Al} \mathrm{K}$-alpha excitation source. Two locations on each sample were analyzed; at the top and bottom of the implant screw. The mean values were calculated.

\section{Mechanical characterization}

Since heat treatment was involved in the coating of the implants, it was of interest to evaluate how the heat treatment affected the mechanical strength of the PEEK material. Mechanical testing was performed in accordance with the tensile testing standard, International Organization for Standardization (ISO) 527-2. Samples for the testing were provided by Invibio Ltd. The specimens were of type $1 \mathrm{~A}$ in the ISO 527 standard, with a total length of $200 \mathrm{~mm}$, a thickness of $4 \mathrm{~mm}$, and a midsection width of $10 \mathrm{~mm}$. The samples were heat-treated at $300^{\circ} \mathrm{C}$ and $350^{\circ} \mathrm{C}$ for 10 minutes, ie, a time twice as long as used when applying the HA coating. Five samples were tested at each temperature. The measurements were performed by Swerea IVF AB (Mölndal, Sweden). An MTS 20/M (MTS Systems Corporation, Eden Prairie, MN, USA) was used for each measurement.

\section{Contact angle measurements}

The contact angles of the test and control surfaces were measured with a DAT 1100 from FIBRO System (Hägersten, Sweden). Water (Type 1, 18.2 M $\Omega$ ) was used as a test liquid and the drop volume was $4 \mu \mathrm{L}$. The measurements were done on PEEK discs since contact angle measurements on threaded surfaces are difficult to interpret.

\section{Surgical procedure and removal torque (RTQ)}

The surgical protocol of the current study was approved by the Malmö/Lund, Sweden, Regional Animal Ethics Committee. Twenty-four Swedish lop-eared rabbits of mixed sex and with a mean weight of $4.1 \mathrm{~kg}$ were selected for the study. On the day of surgical intervention, after fasting, the animals were administered a dose of $0.15 \mathrm{~mL} / \mathrm{kg}$ medetomidine $(1 \mathrm{mg} / \mathrm{mL}$ Dormitor $^{\circledR}$; Orion Pharma AB, Sollentuna, Sweden) and $0.35 \mathrm{~mL} / \mathrm{kg}$ ketamine hydrochloride $\left(50 \mathrm{mg} / \mathrm{mL}\right.$ Ketalar $^{\circledR}$; Pfizer AB, Sollentuna, Sweden) via a vein in the ear. The lower extremities were shaved and washed with $70 \%$ ethanol (Solveco AB, Rosersberg, Sweden) and $5 \mathrm{mg} / \mathrm{mL}$ chlorhexidine (Fresenius Kabi AB, Bad Homburg, Germany). After injection of approximately $1 \mathrm{~mL}$ local anesthesia (Xylocaine; AstraZeneca AB, Södertälje, Sweden), an incision was made along the proximal tibial epiphyseal and the margo cranialis tibiae was exposed. Osteotomy was performed with a series of drills under external continuous irrigation until a final diameter of $3.2 \mathrm{~mm}$ was reached. Prior to implant insertion, the preparation site was tapped in order to minimize shear on implant and coating. The implants were implanted by hand 
until they were fully submerged into the bone. The soft tissues were closed in separate layers, fascia, and subcutaneously with bioresorbable sutures (Ethicon, Norderstedt, Germany). Analgesic buprenorphine hydrochloride $(0.5 \mathrm{~mL}$ Temgesic; Reckitt Benckiser, Slough, UK) was administrated for 3 days post-surgically. After 3 and 12 weeks of healing, the animals were euthanized with an overdose of sodium pentobarbital (60 mg/mL; Apoteksbolaget AB, Stockholm, Sweden). The tibias were retrieved and the soft tissue was removed. In order to measure the RTQ, a digital torque meter (Tohnichi Mfg. Co. Ltd., Ota-Ku, Japan) was connected to the implant driver and then to the implant. The RTQ was measured by counterclockwise rotation.

\section{Statistical analysis}

Statistical analyses were carried out using SPSS Version 20 software (IBM Corporation, Armonk, NY, USA). The topographical values were analyzed with independent samples Student's $t$-tests. Values from the bilaterally RTQs were submitted to the non-parametric Wilcoxon signed-rank test. The level of statistical significance was set at 0.05 .

\section{Results}

\section{Surface characterization}

\section{Interferometry}

The interferometry measurements generated threedimensional images as well as roughness values, which are presented in Table 1. The test group revealed the highest $\mathrm{S}_{\mathrm{a}}$ and the lowest $\mathrm{S}_{\mathrm{dr}}$; however, without statistical significance ( $P=0.556, P=0.849$, respectively). The $\mathrm{S}_{\mathrm{ds}}$ was significantly higher in the control samples $(P=0.002)$. Both surfaces present a minimally rough appearance $\left(\mathrm{S}_{\mathrm{a}}: 0.5-1.0 \mu \mathrm{m}\right)$ according to a recognized surface classification of dental implants. ${ }^{33}$

\section{SEM}

Surface morphology from the SEM analysis is presented in Figure 2. The HA-coated implants presented a random

Table I Mean values for $S_{a}, S_{d r}$, and $S_{d s}( \pm S D)$ for topographical analyses of implants with interferometer and $P$-values for oneway ANOVA comparisons

\begin{tabular}{llll}
\hline Mean $\pm \mathbf{S D}$ & $\mathbf{S}_{\mathrm{a}}(\mu \mathrm{m})$ & $\mathbf{S}_{\mathrm{dr}}(\%)$ & $\mathbf{S}_{\mathrm{ds}}\left(\mu \mathbf{m}^{-2}\right)$ \\
\hline Control & $0.655(0.23 \mathrm{I})$ & $53.3(67.7)$ & $\mathrm{I} 85,532(38,873)$ \\
Test & $0.686(0.140)$ & $50.6(23.8)$ & $157,794(20,78 \mathrm{I})$ \\
$P$-value & 0.556 & 0.849 & 0.002 \\
\hline
\end{tabular}

Notes: $\mathrm{n}=6 ; \mathrm{S}_{\mathrm{a}}(\mu \mathrm{m})=$ average deviation in height in relation to a prenominal plane; $\mathrm{S}_{\mathrm{ds}}\left(\mu \mathrm{m}^{-2}\right)=$ density of summits, a spatial parameter; and $\mathrm{S}_{\mathrm{dr}}(\%)=$ the developed surface ratio to a flat surface.

Abbreviations: ANOVA, analysis of variance; SD, standard deviation. arrangement of HA rods covering the surface at the nanoscale level, whilst the control surfaces were relatively smooth at the same magnification. At the micrometer level, both surfaces presented similar roughness. The turning process caused striations and irregularities, which can be seen on the control surface at the lower magnification. The HA coating on the test implants evens out this orientation of surface features.

\section{XPS}

The XPS spectra for the uncoated and coated implants are shown in Figures 3A and B, respectively. Table 2 shows the atomic concentrations calculated from the spectra. Surfaces of the control samples reveal the presence of carbon, oxygen, and low levels of unexpected contaminations. The test samples showed the presence of carbon and oxygen, but also calcium and phosphorus from the HA crystals. The test samples had higher oxygen content, most probably from the HA crystals, which have a theoretical oxygen atomic content of around $62 \%$. The carbon content on the test samples was lowered from $88.8 \%$ to $55.5 \%$, a logical effect since the carbon-rich PEEK surface becomes shielded by the HA crystals. The $\mathrm{Ca} / \mathrm{P}$ ratio was 1.41 , which differs from the theoretical $\mathrm{Ca} / \mathrm{P}$ ratio for $\mathrm{HA}$ of 1.67 . Due to the semiquantitative nature of XPS, the difference in $\mathrm{Ca} / \mathrm{P}$ is well within the error margin.

\section{Mechanical testing}

Figures $4 \mathrm{~A}-\mathrm{C}$ show the stress-strain curves obtained from tensile testing; as seen from these figures, the stress-strain performance for the samples are virtually identical. A summary of the tensile testing is presented in Table 3 . The elastic modulus was measured to be approximately $4.2 \mathrm{GPa}$, which is in the same range as specified by the PEEK manufacturer. From these data, it can be concluded that the heat treatment that is part of the coating procedure does not alter the mechanical properties of PEEK.

\section{Contact angle measurements}

Contact angles were measured on uncoated and HAcoated discs and were found to be $53^{\circ}$ (SD: 4.4) and $88^{\circ}$ (SD: 2.7), respectively.

\section{Surgical procedure and RTQ}

No signs of infection of the surgical sites were observed during or after the healing periods for all animals. No implants were lost, but one of the rabbits that had been operated on died before sacrifice for unknown reasons. 

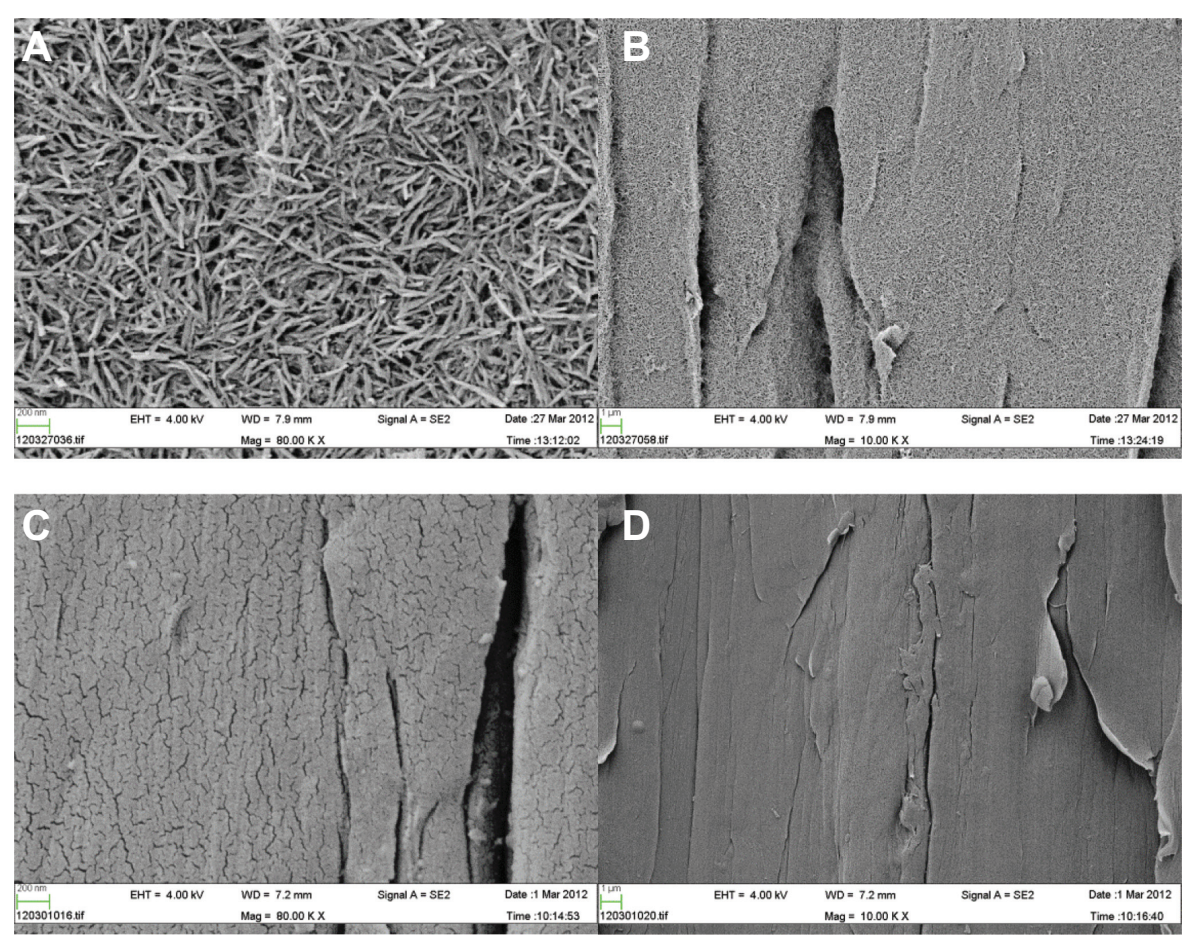

Figure 2 SEM images of HA-coated PEEK at (A) $80 \mathrm{k}$ magnification and (B) $10 \mathrm{k}$ magnification and uncoated PEEK at (C) $80 \mathrm{k}$ magnification and (D) $10 \mathrm{k}$ magnification. Abbreviations: SEM, scanning electron microscopy; PEEK, polyether ether ketone.

A

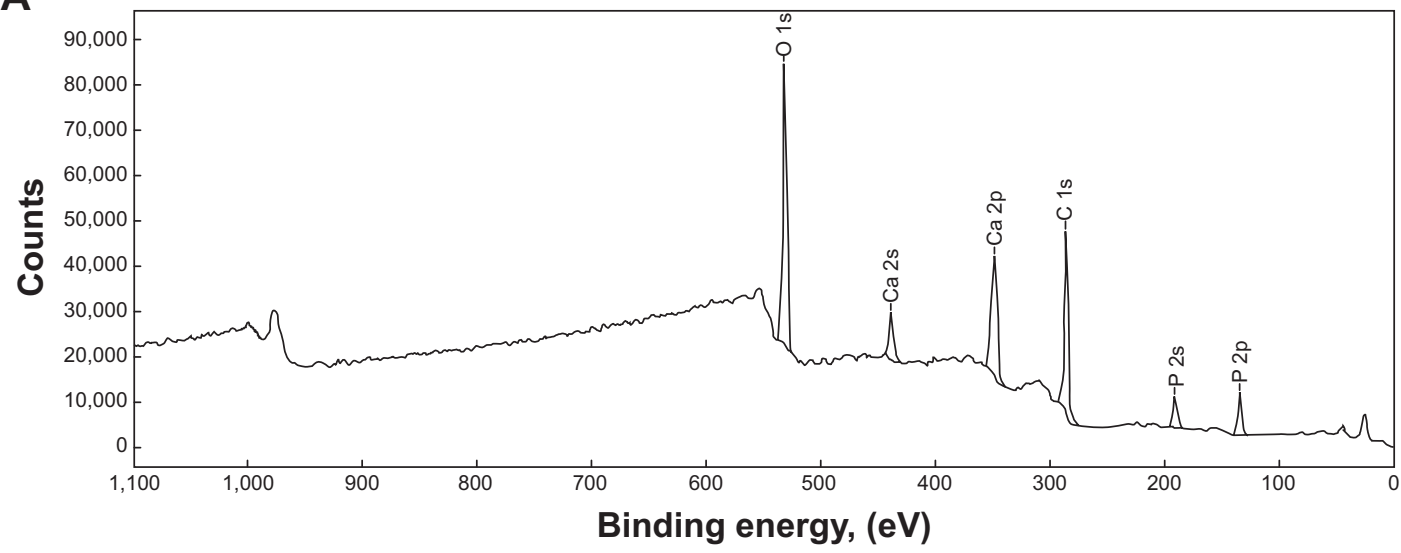

B

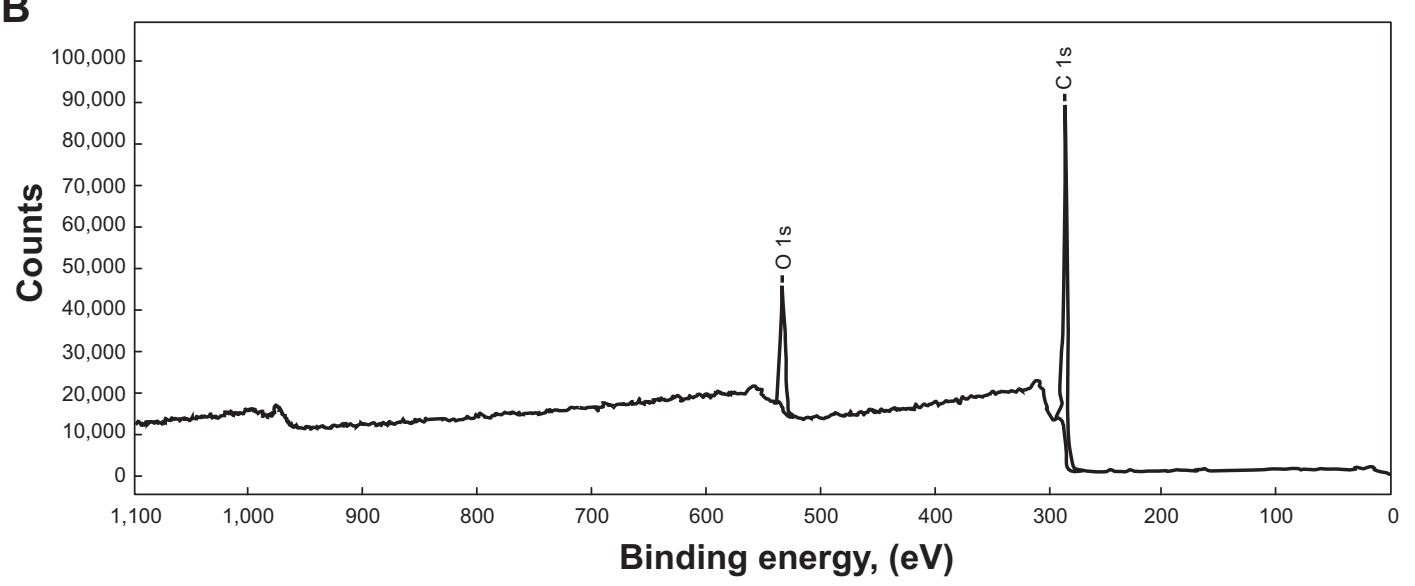

Figure 3 Typical XPS survey spectra of (A) HA-coated surface and (B) control surface. Abbreviations: HA, hydroxyapatite; XPS, X-ray photon spectroscopy. 
Table 2 Elemental compositions from the XPS data of test and control surfaces

\begin{tabular}{lll}
\hline Atom & Test (\%) & Control (\%) \\
\hline $\mathrm{C}$ & 88.8 & 55.5 \\
$\mathrm{Ca}$ & 0 & 8.8 \\
$\mathrm{O}$ & 11.2 & 29.5 \\
$\mathrm{P}$ & 0 & 6.2 \\
\hline
\end{tabular}

Note: Atomic concentration in percentage (\%).

Abbreviation: XPS, X-ray photon spectroscopy.

The mean and standard deviation of RTQ measurements for both groups are illustrated in Table 4 and Figure 5. The RTQ values for the control and test groups after 3 weeks of healing were $7.18 \mathrm{~N} \cdot \mathrm{cm}$ and $13 \mathrm{~N} \cdot \mathrm{cm}$, respectively. After 12 weeks of healing for the control and HA-coated groups, the RTQ values were $5.58 \mathrm{~N} \cdot \mathrm{cm}$ and $9.75 \mathrm{~N} \cdot \mathrm{cm}$, respectively. The mean values were higher for the test group after both healing periods ( 3 weeks: $P=0.008 ; 12$ weeks: $P=0.018$ ) and statistical analysis showed significant differences between the control and test implants for both evaluation times.

\section{Discussion}

The present study was performed to evaluate the effect of a nano HA coating on PEEK implants after 3 and 12 weeks of healing in rabbit tibia. Three weeks represents an early healing time and 12 weeks is when rapid increase in bone turnover healing is expected to have ceased. The unique feature of the test implants was the nanocrystalline surface with a $20 \mathrm{~nm}$ thick HA layer, which was hypothesized to promote the biocompatibility and bioactivity of the PEEK surface and further enhance and accelerate osseointegration. Furthermore, the thickness of the coated layer is believed to possess higher interfacial shear strength and in that way minimize the risk of coating delamination. A histological section, stained with toluidine blue, was cut from a deceased rabbit after 12 weeks of bone healing, and shows signs of new bone and several active osteocytes adjacent to the implant surface. There were no giant cells or similar indicating inflammatory response (Figure 6).
The mechanical testing showed that the heat treatment involved in the coating process did not affect the elastic modulus and the peak stress of the material. The heat treatment was carried out at $325^{\circ} \mathrm{C}$, which is well above the glass transition point of the polymer $\left(143^{\circ} \mathrm{C}\right)$ and close to its melting point $\left(343^{\circ} \mathrm{C}\right) .{ }^{34}$ This may affect the crystallinity of the polymer and therefore also change its mechanical properties. ${ }^{35}$ One explanation for the unchanged mechanical properties is probably the short duration of the heat treatment, heating at $325^{\circ} \mathrm{C}$ for longer time periods may well affect the mechanical stability.

The lower contact angle of the coated surfaces is not surprising since HA is a hydrophilic material. In comparison, previous measurements on rough $(\sim 1.5 \mu \mathrm{m})$ HA-coated titanium have shown contact angles of around $10^{\circ}$. The reason for the higher contact angles on HA-coated PEEK could be that the surface was not fully covered with HA crystals, and/or an effect of the relatively smooth PEEK surface; the surface roughness of a substrate is known to affect the contact angle.

The mean RTQ values were significantly higher for test implants after both evaluation periods. The findings from the present study correlate with several previous studies where HA-coated titanium is evaluated in terms of osseointegration and RTQ. ${ }^{36-40}$ Yet, absolute RTQ values are highly distributed and it is difficult to compare one study to another due to implant design, surgical technique, animal species, and specific substrate material. Generally, the referred studies have found that retention significantly increases for titanium implants coated with HA after 2-6 weeks of healing. Furthermore, after a complete bone turnover, the retention has been found to be similar between the coated and uncoated samples. ${ }^{37}$ However, the finding of increased early retention of HA-coated titanium implants corresponds to the results from this study. ${ }^{37}$ It should be noted that these studies evaluated the retention of titanium implants, not PEEK. On the other hand, Nakahara et $\mathrm{al}^{40}$ examined the interfacial
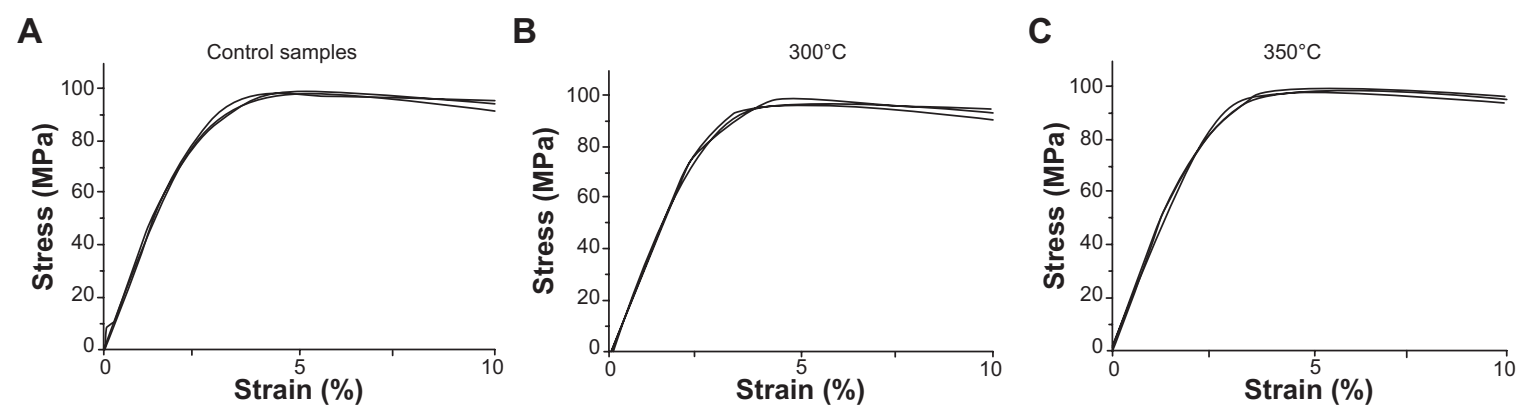

Figure 4 Stress-strain curves for $(\mathbf{A})$ control samples with no heat treatment, (B) $300^{\circ} \mathrm{C}$, and (C) $350^{\circ} \mathrm{C}$. 
Table 3 Summary of tensile testing

\begin{tabular}{llllll}
\hline Sample & Peak load $(\mathbf{N})$ & Peak stress $\mathbf{( M P a )}$ & Modulus $\mathbf{( M P a )}$ & Strain at peak $(\%)$ & Break load $(\mathbf{N})$ \\
\hline Control & 3,997 & 98.0 & 4,211 & 4.943 & 3,418 \\
$300^{\circ} \mathrm{C}$ & 4,009 & 98.2 & 4,209 & 4.726 & 3,384 \\
$350^{\circ} \mathrm{C}$ & 4,050 & 99.2 & 4,184 & 4.839 & 3,390 \\
\hline
\end{tabular}

shear strength with an RTQ test of HA-coated PEEK and titanium implants. The test implants were cylindrical and HA granules were pressed onto the surface and exposed by blasting the surface with alumina beads. Unlike the present study, Nakahara et al evaluated osseointegration by pull-out removal instead of torque removal. Uncoated implants were used as the control and evaluation was completed after 6 and 12 weeks of healing. The RTQ test showed that HA-coated PEEK holds higher retention than all the other samples. The retention for HA-coated PEEK also increased after 12 weeks compared to 6 weeks, but not significantly. This indicates that the effect of HA coating is final at an earlier stage regardless of substrate material. In contrast, titanium showed increased interfacial shear at 12 weeks, which may be explained by bone-titanium integration. ${ }^{40}$

HA is an endogenous substance that can be found within osteoblast and osteoclast cells. After a cascade of actions in the cell, HA crystals will exit the cell and bind onto collagen molecules and initiate mineralization. ${ }^{41}$ By adding HA to an implant surface, mineralization may be stimulated at an early stage by forming new sites of initiation that can increase the amount and density of surrounding bone. Several studies have proven HA to be an effective coating substance to increase bone-screw interfaces. ${ }^{42,43}$ The size and shape of the deposited HA crystals in this study are similar to that in bone. Furthermore, nanoscale HA-coated implants may exceed micron-scale HA coatings in implant retention and histopathologic results. ${ }^{44}$ By incorporating HA onto the implant surface, not only are the chemical properties altered but also the surface topography. ${ }^{30}$ Surface topography can also be modified by exposing the surface to an accelerated neutral atom beam, and has successfully resulted in increased biocompatibility of PEEK. The authors explained that the increased biocompatibility was related to the surface nanometer texture, which

Table 4 Mean \pm SD removal torque force $(N \cdot \mathrm{cm})$ for control and test groups

\begin{tabular}{lll}
\hline Mean \pm SD & 3 weeks & I 2 weeks \\
\hline Control & $7.18(2.96)$ & $5.58(2.07)$ \\
Test & $13(5.2)$ & $9.75(4.65)$ \\
$P$-value & 0.05 & 0.028 \\
\hline
\end{tabular}

Note: $\mathrm{n}=23$.

Abbreviation: SD, standard deviation. enhanced cell attachment and proliferation. ${ }^{45}$ The results from this study correspond to the finding that nanoscale surface modification enhances RTQ and wettability, which together enhance the biocompatibility of PEEK. The numerical data on the micrometer level as evaluated with an interferometer revealed more dense peaks on the surface of the control group samples. However, the resolution of the interferometer is on the micrometer level and the applied surface modification is altering the surface at the nanoscale level. Barkarmo et al evaluated PEEK in vivo with the same rabbit model as in the present study. The surface properties of the coating and histomorphometry indicate that the HA-coated implants had more contact with bone (16\% $\pm 4.7 \%$ vs $13 \% \pm 9.3 \%)$ and more bone area $(52 \% \pm 9.5 \%$ vs $45 \% \pm 11.9 \%)$. However, there were large numbers of lost implants due to loss of primary stability since the implants lacked threads. ${ }^{31}$ Therefore, the implant was redesigned and now possesses wide and shallow threads for primary stability to allow initial osseointegration. The implant was also designed to be fully submerged into the bone to minimize external loading during healing.

The results from the current study showed that the RTQ value was lower after 12 weeks when compared to 3 weeks for both test and control samples. A credible explanation for this tendency remains unknown. However, for the coated implants, a possible explanation may be the dissolution of HA particles from the surface, which has been previously studied in a rat model. ${ }^{46}$ Further studies are required to investigate the continued RTQ with a longer healing time to increase clinical relevance.

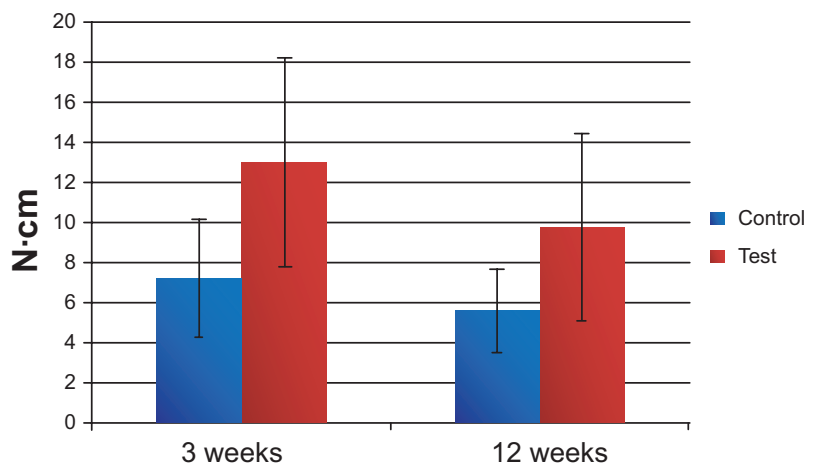

Figure 5 Mean values and standard deviation of removal torque $(\mathrm{N} \cdot \mathrm{cm})$ at both healing periods. 


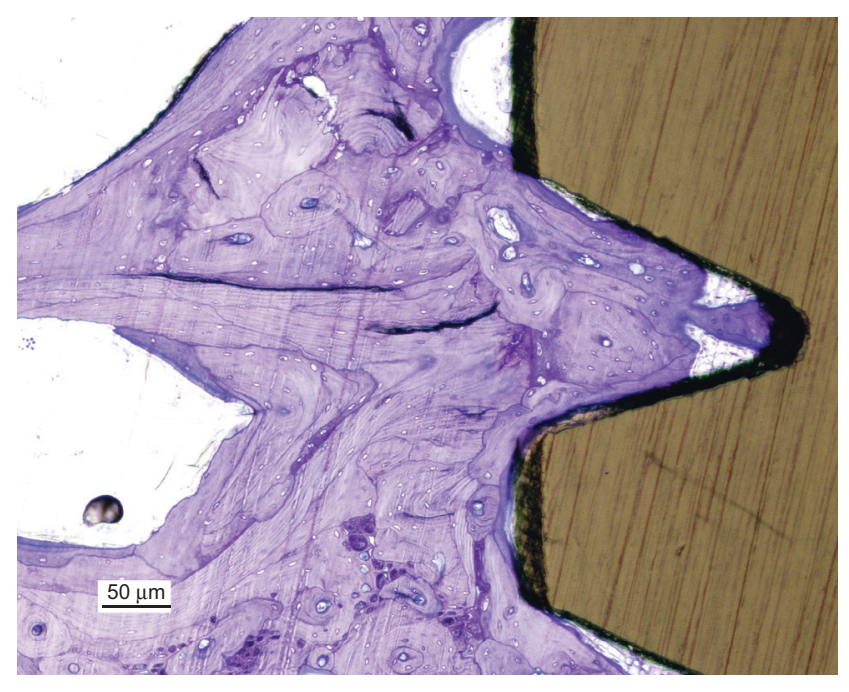

Figure 6 Histological section of the bone to implant interface, stained with toluidine blue.

\section{Conclusion}

The results of the present study indicate that the biocompatibility of PEEK can be improved with spin-coated nanosized HA. The application of the HA coating does not affect the mechanical strength of the PEEK. Evidence for this biocompatibility was derived from the increased RTQ. These results indicate that chemical inert materials such as PEEK can be converted into a suitable biomaterial for demanding orthopedic applications.

\section{Acknowledgment}

This study was supported by grants received from the Swedish Knowledge Foundation.

\section{Disclosure}

The authors report no conflicts of interest in this work.

\section{References}

1. Katzer A, Marquardt H, Westendorf J, Wening JV, von Foerster G. Polyetheretherketone - cytotoxicity and mutagenicity in vitro. Biomaterials. 2002;23(8):1749-1759.

2. Ulrich D, Edwards SL, White JF, et al. A preclinical evaluation of alternative synthetic biomaterials for fascial defect repair using a rat abdominal hernia model. PloS One. 2012;7(11):e50044.

3. Williams D. Polyetheretherketone for long-term implantable devices. Med Device Technol. 2008;19(1):8, 10-11.

4. Toth JM, Wang M, Estes BT, Scifert JL, Seim HB 3rd, Turner AS. Polyetheretherketone as a biomaterial for spinal applications. Biomaterials. 2006;27(3):324-334.

5. Rabiei A, Sandukas S. Processing and evaluation of bioactive coatings on polymeric implants. J Biomed Mater Res A. 2013;101(9):2621-2629.

6. Nieminen T, Kallela I, Wuolijoki E, Kainulainen H, Hiidenheimo I, Rantala I. Amorphous and crystalline polyetheretherketone: mechanical properties and tissue reactions during a 3-year follow-up. J Biomed Mater Res A. 2008;84(2):377-383.

7. Kurtz SM, Devine JN. PEEK biomaterials in trauma, orthopedic, and spinal implants. Biomaterials. 2007;28(32):4845-4869.
8. Evans SL, Gregson PJ. Composite technology in load-bearing orthopaedic implants. Biomaterials. 1998;19(15):1329-1342.

9. Ponnappan RK, Serhan H, Zarda B, Patel R, Albert T, Vaccaro AR. Biomechanical evaluation and comparison of polyetheretherketone rod system to traditional titanium rod fixation. Spine J. 2009;9(3): 263-267.

10. Walter J, Kuhn SA, Reichart R, Kalff R, Ewald C. PEEK cages as a potential alternative in the treatment of cervical spondylodiscitis: a preliminary report on a patient series. Eur Spine J. 2010;19(6):1004-1009.

11. Niu CC, Liao JC, Chen WJ, Chen LH. Outcomes of interbody fusion cages used in 1 and 2-levels anterior cervical discectomy and fusion: titanium cages versus polyetheretherketone (PEEK) cages. J Spinal Disord Tech. 2010;23(5):310-316.

12. Wang HR, Li XL, Dong J, Yuan FL, Zhou J. Skip-level anterior cervical discectomy and fusion with self-locking stand-alone PEEK cages for the treatment of two noncontiguous levels of cervical spondylosis. J Spinal Disord Tech. 2013;26(7):E286-E292.

13. Cutler AR, Siddiqui S, Mohan AL, Hillard VH, Cerabona F, Das K. Comparison of polyetheretherketone cages with femoral cortical bone allograft as a single-piece interbody spacer in transforaminal lumbar interbody fusion. $J$ Neurosurg Spine. 2006;5(6):534-539.

14. Kulkarni AG, Hee HT, Wong HK. Solis cage (PEEK) for anterior cervical fusion: preliminary radiological results with emphasis on fusion and subsidence. Spine J. 2007;7(2):205-209.

15. Wong KL, Wong CT, Liu WC, et al. Mechanical properties and in vitro response of strontium-containing hydroxyapatite/polyetheretherketone composites. Biomaterials. 2009;30(23-24):3810-3817.

16. Abu Bakar MS, Cheng MH, Tang SM, et al. Tensile properties, tension-tension fatigue and biological response of polyetheretherketonehydroxyapatite composites for load-bearing orthopedic implants. Biomaterials. 2003;24(13):2245-2250.

17. Yang GL, He FM, Song E, Hu JA, Wang XX, Zhao SF. In vivo comparison of bone formation on titanium implant surfaces coated with biomimetically deposited calcium phosphate or electrochemically deposited hydroxyapatite. Int J Oral Maxillofac Implants. 2010;25(4):669-680.

18. Park DS, Kim IS, Kim H, et al. Improved biocompatibility of hydroxyapatite thin film prepared by aerosol deposition. J Biomed Mater Res $B$ Appl Biomater. 2010;94(2):353-358.

19. Zhang H, Wang S, Zhao B. [Histocompatibility of porous hydroxyapatite coating NiTi shape memory alloy]. [Zhongguo xiu fu chong jian wai ke za zhi=Zhongguo xiufu chongjian waike zazhi]. Chin J Repar Reconstruct Surg. 2009;23(4):468-472. Chinese.

20. Hermida JC, Bergula A, Dimaano F, Hawkins M, Colwell CW Jr, D'Lima DD. An in vivo evaluation of bone response to three implant surfaces using a rabbit intramedullary rod model. J Orthop Surg Res. 2010;5:57.

21. Lee JH, Jang HL, Lee KM, et al. In vitro and in vivo evaluation of the bioactivity of hydroxyapatite-coated polyetheretherketone biocomposites created by cold spray technology. Acta biomater. 2013;9(4): 6177-6187.

22. Bonfante EA, Witek L, Tovar N, et al. Physicochemical characterization and in vivo evaluation of amorphous and partially crystalline calcium phosphate coatings fabricated on Ti-6Al-4V implants by the plasma spray method. Int J Biomater. 2012;2012:603826.

23. Manders PJ, Wolke JG, Jansen JA. Bone response adjacent to calcium phosphate electrostatic spray deposition coated implants: an experimental study in goats. Clin Oral Implants Res. 2006;17(5):548-553.

24. Albrektsson T. Hydroxyapatite-coated implants: a case against their use. J Oral Maxillofac Surg. 1998;56(11):1312-1326.

25. Røkkum M, Reigstad A, Johansson CB, Albrektsson T. Tissue reactions adjacent to well-fixed hydroxyapatite-coated acetabular cups. Histopathology of ten specimens retrieved at reoperation after 0.3 to 5.8 years. J Bone Joint Surg Br. 2003;85(3):440-447.

26. Reigstad O, Johansson C, Stenport V, Wennerberg A, Reigstad A, Røkkum M. Different patterns of bone fixation with hydroxyapatite and resorbable $\mathrm{CaP}$ coatings in the rabbit tibia at 6,12 , and 52 weeks. J Biomed Mater Res B Appl Biomater. 2011;99(1):14-20. 
27. Meirelles L, Arvidsson A, Andersson M, Kjellin P, Albrektsson T, Wennerberg A. Nano hydroxyapatite structures influence early bone formation. J Biomed Mater Res A. 2008;87(2):299-307.

28. Svanborg LM, Hoffman M, Andersson M, Currie F, Kjellin P, Wennerberg A. The effect of hydroxyapatite nanocrystals on early bone formation surrounding dental implants. Int J Oral Maxillofac Surg. 2011; 40(3):308-315.

29. Munir G, Koller G, Di Silvio L, Edirisinghe MJ, Bonfield W, Huang J. The pathway to intelligent implants: osteoblast response to nano silicon-doped hydroxyapatite patterning. JR Soc Interface. 2011;8(58): 678-688.

30. Meirelles L, Currie F, Jacobsson M, Albrektsson T, Wennerberg A. The effect of chemical and nanotopographical modifications on the early stages of osseointegration. Int J Oral Maxillofac Implants. 2008; 23(4):641-647.

31. Barkarmo S, Wennerberg A, Hoffman M, et al. Nano-hydroxyapatitecoated PEEK implants: a pilot study in rabbit bone. J Biomed Mater Res A. 2013;101(2):465-471.

32. Wennerberg A, Albrektsson T. Suggested guidelines for the topographic evaluation of implant surfaces. Int J Oral Maxillofac Implants. 2000;15(3):331-344.

33. Albrektsson T, Wennerberg A. Oral implant surfaces: Part 1 - review focusing on topographic and chemical properties of different surfaces and in vivo responses to them. Int J Prosthodont. 2004;17(5):536-543.

34. Kurtz SM; Plastics Design Library. PEEK Biomaterials Handbook. 1st edition. Waltham, MA: William Andrew; 2012.

35. Hay JN, Langford JI, Lloyd JR. Variation in unit cell parameters of aromatic polymers with crystallization temperature. Polymer. 1989;30(3):489-493.

36. Sandén B, Olerud C, Larsson S. Hydroxyapatite coating enhances fixation of loaded pedicle screws: a mechanical in vivo study in sheep. Eur Spine J. 2001;10(4):334-339.

37. Eom TG, Jeon GR, Jeong CM, et al. Experimental study of bone response to hydroxyapatite coating implants: bone-implant contact and removal torque test. Oral Surg Oral Med Oral Pathol Oral Radiol. 2012;114(4):411-418.
38. Cheng Z, Guo C, Dong W, He FM, Zhao SF, Yang GL. Effect of thin nano-hydroxyapatite coating on implant osseointegration in ovariectomized rats. Oral Surg Oral Med Oral Pathol Oral Radiol. 2012; 113(3):e48-e53.

39. Park YS, Yi KY, Lee IS, Han CH, Jung YC. The effects of ion beamassisted deposition of hydroxyapatite on the grit-blasted surface of endosseous implants in rabbit tibiae. Int J Oral Maxillofac Implants. 2005;20(1):31-38

40. Nakahara I, Takao M, Goto T, Ohtsuki C, Hibino S, Sugano N. Interfacial shear strength of bioactive-coated carbon fiber reinforced polyetheretherketone after in vivo implantation. J Orthop Res. 2012; 30(10):1618-1625.

41. Anderson HC. Molecular biology of matrix vesicles. Clin Orthop Relat Res. 1995;(314):266-280.

42. Yildirim OS, Aksakal B, Celik H, Vangolu Y, Okur A. An investigation of the effects of hydroxyapatite coatings on the fixation strength of cortical screws. Med Eng Phys. 2005;27(3):221-228.

43. Yildirim OS, Aksakal B, Hanyaloglu SC, Erdogan F, Okur A. Hydroxyapatite dip coated and uncoated titanium poly-axial pedicle screws: an in vivo bovine model. Spine (Phila Pa 1976). 2006;31(8): E215-E220.

44. Aksakal B, Kom M, Tosun HB, Demirel M. Influence of micro- and nano-hydroxyapatite coatings on the osteointegration of metallic (Ti6Al4 V) and bioabsorbable interference screws: an in vivo study. Eur J Orthop Surg Traumatol. Epub 2013 May 21.

45. Khoury J, Kirkpatrick SR, Maxwell M, Cherian RE, Kirkpatrick A, Svrluga RC. Neutral atom beam technique enhances bioactivity of PEEK. Nucl Industr Meth B. 2013;(307):630-634.

46. Wennerberg A, Jimbo R, Allard S, Skarnemark G, Andersson M. In vivo stability of hydroxyapatite nanoparticles coated on titanium implant surfaces. Int J Oral Maxillofac Implants. 2011;26(6):1161-1166.
International Journal of Nanomedicine

\section{Publish your work in this journal}

The International Journal of Nanomedicine is an international, peerreviewed journal focusing on the application of nanotechnology in diagnostics, therapeutics, and drug delivery systems throughout the biomedical field. This journal is indexed on PubMed Central, MedLine, CAS, SciSearch $®$, Current Contents $\AA /$ Clinical Medicine,

\section{Dovepress}

Journal Citation Reports/Science Edition, EMBase, Scopus and the Elsevier Bibliographic databases. The manuscript management system is completely online and includes a very quick and fair peer-review system, which is all easy to use. Visit http://www.dovepress.com/ testimonials.php to read real quotes from published authors. 